\title{
Fertility Decisions and Contraceptive Use at Different Stages of Relationships: Windows of Risk Among Men And Women in Accra
}

\begin{abstract}
CONTEXT: Despite declining fertility in Ghana, modern contraceptive use-even in urban areas-is low for reasons that remain unclear. Few studies have explored what drives fertility decisions and contraceptive use among contemporary urban residents within a relationship context.
\end{abstract}

METHODS: In-depth contraceptive life history interviews were conducted among a purposive sample of 80 sexually active women and men living in Accra.

RESULTS: Contraception is viewed favorably, although the timing and choice of method strongly depends on the type and stage of relationship. At sexual debut and at first sex with a new partner, sex is usually unprotected. Many women show agency in subsequently negotiating condom use; men also show motivation to practice contraception. As relationships stabilize, couples abandon condoms and adopt traditional methods, out of fear that modern methods could affect fertility. After a first birth, couples prefer modern contraceptives to space children, but side effects often lead women to switch methods or discontinue use; women in supportive relationships are more likely than those in unsupportive relationships to continue use of modern contraceptives despite side effects. After reproductive goals have been realized, couples revert to using traditional methods to avoid further exposure to "chemicals."

CONCLUSIONS: Contraceptive programs may be more successful if they target messages according to stage of relationship, involve men and work with people's desires to use traditional methods at certain times to ensure that they can do so safely.

International Perspectives on Sexual and Reproductive Health, 2014, 40(3):135-143, doi: 10.1363/4013514
By Ivy Frances Osei, Susannah Harding Mayhew, Leticia Biekro, Martine Collumbien and the ECAF Team

Ivy Frances Osei is deputy director and Leticia Biekro is researcher-both with Health Research \& Development Division, Ghana Health Service, Accra, Ghana. Susannah Harding Mayhew is reader and Martine Collumbien is senior lecturer-both with London School of Hygiene \& Tropical Medicine, London.
In Ghana, fertility has declined steadily over several decades, from 6.5 children per woman in 1979 to 4.0 in 2008. ${ }^{1}$ Current modern contraceptive use among married women, however, has risen slowly, from 13\% in 1998 to $17 \%$ in $2008 .{ }^{1,2}$ Ever-use of a modern method among all women has increased more quickly, from 21\% in 1988 to $42 \%$ in 2008; the 2008 rate among all men was similar (46\%). Overall contraceptive prevalence in Ghana has been characterized by a persistence of traditional method use: $^{{ }^{2-4}}$ Twenty-five percent of all women report ever-use of a traditional method. ${ }^{2}$

The picture in Ghana is very different from that seen in eastern and southern African countries with similar rates of fertility decline, where the driving force has been increased modern contraceptive use. ${ }^{2-4}$ Explanations other than contraceptive use have been proposed for Ghana's fertility decline, including underreporting of contraceptive use by women and the control of fertility through reduced coital frequency. ${ }^{3,5}$ Widespread use of induced abortion may also be a major contributing factor in fertility decline in Ghana. ${ }^{1}$ Although abortion is legal in Ghana within

*According to the criminal code of Ghana, abortion is legal if performed by a medical practitioner in a designated facility for cases involving rape, incest or fetal abnormality, or to protect the physical or mental health of the mother. broadly defined limits, ${ }^{*}$ health care providers and clients commonly believe it to be illegal, ${ }^{6}$ and access to safe abortion services is poor. ${ }^{7}$

Ghana has good socioeconomic indicators, including women's primary education, and the country attained lower middle income status in 2011. ${ }^{2}$ Ghana was one of the first countries in Sub-Saharan Africa to engage in family planning activities, although political commitment has varied over time. ${ }^{8} \mathrm{~A}$ wide range of contraceptive methods is available in both the public and private sectors, including pharmacies. Ninety-eight percent of all women and men in Ghana know at least one method of contraception. ${ }^{1}$

Studies on the perceptions and use of contraceptives in Ghana are predominantly from the Navrongo-based demographic surveillance site and rural contraception project in the country's north. ${ }^{9-12}$ Far fewer such studies focus on urban Ghana, ${ }^{13}$ where family planning use is lower than expected. For example, in 2008, the total fertility rates for urban and rural areas were 3.1 and 4.9, respectively, yet current contraceptive use among married women differed little by location (19\% and 15\%). ${ }^{1}$ With a steadily increasing rate of urbanization (currently at 44\%), ${ }^{2}$ understanding contraceptive dynamics in urban Ghana is particularly important.

Previous research has demonstrated shifting social 
norms around sexuality in contemporary urban Ghana, where it is now more common for single women to engage in sexual relationships; ${ }^{14,15}$ however, to our knowledge, no studies have explored how individuals in Ghana make decisions about fertility and contraceptive use in the context of changing sexual norms and within relationships. In this study, we aim to understand the social and relational contexts in which reproductive decisions are made; we do not consider health facility- or provider-related influences (reported elsewhere ${ }^{16}$ ), except when specifically identified by respondents as a pertinent influence.

We examine three levels of variables found to be associated with contraceptive decision making in Ghana. The individual level includes personal, biological and psychosocial variables such as attitude to contraception, ${ }^{17}$ knowledge and skill (behavioral capacity), ${ }^{18}$ self-efficacy ${ }^{19}$ and outcome expectancy. ${ }^{20}$ Interpersonal factors focus on influence of the sexual partner ${ }^{21}$ and power dynamics within the relationship. ${ }^{22}$ And social factors focus on the social norms and pressures governing sexuality and gender roles, such as expectations for women to be sexually passive to safeguard their dignity and honor. ${ }^{23}$ We draw these variables together to understand the contexts in which men and women make contraceptive decisions through their reproductive lives and at different stages of a sexual relationship. In doing so, we offer a fresh examination of the relationship between these variables and modern contraceptive use in Ghana.

\section{METHODS}

Data were drawn from the Emergency Contraception in Africa (ECAF) study conducted in Burkina Faso, Ghana, Morocco and Senegal; specific findings on emergency contraception are reported elsewhere. ${ }^{15}$ For this qualitative analysis, we used data from in-depth interviews with sexually active male and female residents of Accra, Ghana, conducted between June 2006 and November 2007. We chose Accra because contraceptive prevalence and access to a variety of contraceptives there are the highest in the country and because it is the region of Ghana experiencing the greatest social change. ${ }^{5}$

Predetermined quotas guided the sampling, to get a wide distribution in terms of age, marital and educational status. ${ }^{15}$ Respondents were actively recruited from family planning clinics and pharmacies to supplement sampling through direct contact with people living in the catchment areas in which clinics and pharmacies were located. This purposive sample overrepresents current contraceptive users, as well as more highly educated people.

Potential respondents were briefed about the project and its purpose, and their verbal consent was sought. Those who consented selected a date and venue for individual interviews, which were conducted by three female (including the first and third authors) and two male interviewers; respondents were matched with an interviewer of the same sex. Venues included respondents' workplaces; clinics; homes of interviewers, respondents or friends; the office of the Health Research Unit; under a tree; in an uncompleted building; and in interviewers' cars. Interviews were conducted in the language preferred by respondents: Ewe, Twi/Fante, English or a mixture of English and Twi. All interviews were recorded, and pseudonyms were used throughout the analysis and reporting. Ethical approval was obtained from the Ghana Health Services and the London School of Hygiene \& Tropical Medicine.

All interviews started with a question intended to get the respondent talking about the context in which contraceptive use occurs and help them relax before exploring personal use: "Today we tend to choose our own partners. Do you think this makes for a better relationship?" The rest of the interview was guided by the respondent's answers, although interviewers had a topic guide to ensure that all relevant issues were discussed. Topics included current and previous sexual relationships; contraceptive use, including access, failures and difficulties during all relationships; desire for children; respondents' financial autonomy, living conditions and support network; knowledge, opinion and use of emergency contraception; experience with and opinion on abortion; sexually transmitted infection history; opinions on premarital, polygamous and extramarital affairs; and demographic characteristics.

For each of the 80 respondents ( 26 men and 54 women), we performed a case analysis by constructing a synopsis of the individual's sexual, contraceptive, pregnancy and relationship histories on the basis of their narratives as informed by life-cycle narrative methods. ${ }^{24,25}$ The majority of respondents had experienced more than one relationship, so we had a large sample of relationship stages, from initiation to stable long-term partnerships, which became an important part of our analysis. We constructed a coding frame using major themes from research questions and themes that emerged from the data. ${ }^{26}$ This framework was applied to all transcripts using NVIVO 7, which facilitated cross-case thematic analysis (using Excel ${ }^{\circ}$ spreadsheets to compare interviews and themes) to identify variations across interviews according to respondents' characteristics (age, sex, educational level, relationship status and reproductive history). Contraceptive history and unintended pregnancy experience were analyzed according to background characteristics. We discuss differences in contraceptive motivations and use, by background characteristics that appeared to be important.

\section{RESULTS}

Respondents' age ranged between 18 and 36 years; the majority of men and women were aged 20-30 (Table 1). Twenty-four women had a high level of education (complete secondary or postsecondary), 18 had a medium education (complete primary or incomplete secondary) and 12 had a low education (none or incomplete primary); those numbers among men were 9, 12 and 5. Half of women were currently married, whereas more than half of men were single; 40 women and seven men had living children. Nearly all women and men had ever used a contraceptive 
method, and a majority of each were currently using one. Twenty-three women had had an abortion, and 11 men reported ever having a partner who had had an abortion.

\section{Knowledge and Use of Contraceptives}

Respondents exhibited high levels of awareness of the various contraceptives available in Ghana. The most commonly cited methods were the male condom, the calendar method and the injectable. Others included the pill, the IUD, the implant and spermicides; a few women talked about local preparations (mostly herbal) used for pregnancy prevention. Female sterilization, male sterilization and emergency contraception were mentioned infrequently.

Only four women and one man reported never having used any method. Two of the women had never felt the need, because they had had problems conceiving or carrying a pregnancy to term. The other three cited adverse effects of contraceptives as reasons for nonuse. For example, a man said:

"I'm not interested in the contraceptives...they have side effects. You might not be able to give birth (get pregnant) when you decide to have children."-24-year-old single man with no children, middle education

Current contraceptive use was high: Thirty-eight out of 54 women and 19 out of 26 men reported relying on some method of pregnancy prevention at the time of the interview (Table 1). Overall, methods requiring male participation (condoms, traditional methods or a combination of the two) were the most prevalent (Table 2, page 138), although they are not the most effective at preventing unintended pregnancy. The most common method used by women was the injectable; however, almost as many women used a combination of traditional methods and short-term modern methods (usually condoms or emergency contraception). Sixteen women reported no current contraceptive use. A reason for nonuse could not be established for eight of these women; of the others, two were trying to conceive, and six had no need for contraceptives because they had not resumed sex after a recent delivery, had no partner or were practicing secondary abstinence.

Contraceptive use among men was dominated by the male condom, either by itself or in combination with other methods. Seven men reported nonuse: Four did not have a current partner, the wife of another was pregnant, one had never used a method (citing dislike) and one did not give a reason. One of the male nonusers, however, reported deciding on secondary abstinence, but occasionally relied on emergency contraception when sexually active.

\section{Pattern of Fertility Decisions and Contraceptive Use}

Of all the characteristics analyzed, the relationship stage and the reproductive stage seemed to be the most closely associated with respondents' fertility choices and use of contraceptive methods. By "relationship stage," we mean the stage and nature of the relationship between the respondent and a sexual partner (e.g., first intercourse, new sexual relationship, stable partnership); "reproduc-
TABLE 1. Number of in-depth interview participants, by selected characteristics, Accra, Ghana

\begin{tabular}{|c|c|c|c|}
\hline Characteristic & $\begin{array}{l}\text { Women } \\
(\mathrm{N}=54)\end{array}$ & $\begin{array}{l}\text { Men } \\
(\mathrm{N}=26)\end{array}$ & $\begin{array}{l}\text { All } \\
(\mathrm{N}=80)\end{array}$ \\
\hline \multicolumn{4}{|l|}{ Age } \\
\hline$<20$ & 4 & 1 & 5 \\
\hline $20-25$ & 18 & 8 & 26 \\
\hline $26-30$ & 16 & 10 & 26 \\
\hline 30-35 & 13 & 6 & 19 \\
\hline$>35$ & 3 & 1 & 4 \\
\hline \multicolumn{4}{|l|}{ Education } \\
\hline High & 24 & 9 & 33 \\
\hline Middle & 18 & 12 & 30 \\
\hline Low & 12 & 5 & 17 \\
\hline \multicolumn{4}{|l|}{ Marital status } \\
\hline Marrried & 27 & 9 & 36 \\
\hline Single & 22 & 17 & 39 \\
\hline Divorced/separate/widowed & 5 & 0 & 5 \\
\hline \multicolumn{4}{|l|}{ Children } \\
\hline Yes & 40 & 7 & 47 \\
\hline No & 14 & 19 & 33 \\
\hline \multicolumn{4}{|l|}{ Ever contraceptive use } \\
\hline Yes & 50 & 25 & 75 \\
\hline No & 4 & 1 & 5 \\
\hline \multicolumn{4}{|l|}{ Current contraceptive use } \\
\hline Yes & 38 & 19 & 57 \\
\hline No & 16 & 6 & 23 \\
\hline \multicolumn{4}{|l|}{ Abortion } \\
\hline Yes & 23 & 11 & 34 \\
\hline No & 31 & 15 & 46 \\
\hline
\end{tabular}

Note: For education, high=complete secondary/postsecondary, middle= complete primary/incomplete secondary and low=no/incomplete primary.

tive stage" refers to whether the individual has yet to start childbearing, still wants or may want more children, or has finished childbearing. The discussion below is based on the themes describing the pattern of contraceptive use that emerged over the relationship and reproductive stages of our respondents. At each stage, relevant individual, partner and social influences are highlighted.

- First sexual intercourse is often unprotected. Premarital sex was the norm among women, as only three reported that their first sex had occurred after marriage. Mostly, women's first sexual intercourse had been unprotected and occurred without much consideration of possible pregnancy. For more than one in three, their first sexual experience had involved rape (commonly with alcohol or drugs), coercion or deception; in addition, many women reported not being willing participants at first sex with subsequent partners. Typically, in such circumstances, women's individual agency was circumscribed by male partners who were older and had more social power, and afterwards, the women were blamed for not upholding traditional gender norms. One women who was raped by her friend's brother recounted:

"I was with his sister in her bedroom conversing and he came there. The sister said she was going out to pick something outside. They had planned everything, but I didn't know that. He locked the door and I struggled fiercely 


\begin{tabular}{|c|c|c|c|}
\hline Method & $\begin{array}{l}\text { Women } \\
(\mathrm{N}=54)\end{array}$ & $\begin{array}{l}\text { Men } \\
(N=26)\end{array}$ & $\begin{array}{l}\text { All } \\
(\mathrm{N}=80)\end{array}$ \\
\hline \multicolumn{4}{|l|}{ Modern } \\
\hline Injectable & 13 & 3 & 16 \\
\hline Implant & 3 & 0 & 3 \\
\hline EC & 2 & 1 & 3 \\
\hline Pill & 0 & 1 & 1 \\
\hline IUD & 1 & 0 & 1 \\
\hline Tubal ligation & 1 & 0 & 1 \\
\hline Condom & 3 & 7 & 10 \\
\hline \multicolumn{4}{|l|}{ Traditional } \\
\hline Rhythm & 4 & 0 & 4 \\
\hline Withdrawal & 2 & 1 & 3 \\
\hline \multicolumn{4}{|l|}{ Combination } \\
\hline Rhythm + withdrawal & 1 & 2 & 3 \\
\hline Rhythm + EC & 5 & 1 & 6 \\
\hline Rhythm + condom & 1 & 0 & 1 \\
\hline Rhythm + condom + EC & 0 & 1 & 1 \\
\hline Rhythm + LAM & 1 & 0 & 1 \\
\hline Condom + spermicide & 1 & 0 & 1 \\
\hline Condom + pill & 0 & 2 & 2 \\
\hline None & 16 & 7 & 23 \\
\hline
\end{tabular}

with him. I could not scream because it would seem like I wanted it that was why I had gone into the room." -32year-old married woman with one child, middle education

Although coercion or rape mostly precludes the use of any form of protection, some men reported using condoms in forced sex. One man said:

"She told me that I had to marry her before she would allow me to [have sex] with her....So, I decided to get her drunk, so I gave her a drink. She got drunk, and I had my way with her...I used just the condom."-24-year-old married man with no children, high education

Unlike their female counterparts, all male respondents reported being willing participants at their sexual debut. Indeed, they initiated sexual activity, except in two cases.

When first sex was consensual, some couples had practiced contraception, while others had found themselves in the "heat of the moment." Social norms about women's sexual innocence were common reasons for not expecting anything to happen (even if they were not surprised when it did) and, therefore, for taking no precautions.

- Condoms are favored early in a relationship to prevent STIs and pregnancy. Sexual relationships typically started with the expectation that women would behave as though they were sexually naive and would not initiate sexual activity; however, this initial period was often quite short. Condoms were frequently adopted in the early stages of a relationship, and many women reported exercising individual agency and successfully negotiating condom use, even when their partners initially refused. One woman described:

"I brought up the idea, but he said he doesn't want to use condom because he wanted to marry me. But I said no, we are not staying together so he can go out and bring me some diseases. So, we should use the condom. We quar- reled over it for some time before he agreed to use it, and we are using it."-23-year-old single woman with no children, middle education

Although some women found it hard to persuade men to use condoms, many men reported wanting to use condoms early in a relationship. The dual purpose of condoms was recognized, and use was considered socially acceptable with new partners. Most women and men started out using condoms for both pregnancy prevention and STI prevention, although the latter was more frequently mentioned. One man recalled:

"I wasn't ready for any baby and moreover to prevent the disease which they have been talking about on radio. I didn't want to take any risk, because we had not gone to do any test to determine our status on AIDS or any of the sexually transmitted diseases....That is why I used the condom." -20-year-old single man with no children, middle education

- Couples in unstable relationships favor contraceptive use to prevent pregnancy. In relationships that have progressed, but are unstable, both men and women reported high motivation (and individual agency) to prevent pregnancy. Respondents did not explicitly mention the influence of any social factors when discussing this relationship stage; however, it was clear from their narratives that social norms had shifted to allow women to have sexual relationships before marriage and to seek contraception. Two women whose partners were refusing to marry them reported using the injectable to avoid pregnancy until their partners performed marriage rites. Some men wanted to avoid pregnancy in relationships they knew were not serious and took the initiative to use condoms, withdrawal or the calendar method. One man explained:

"It is important because, if I don't think about it and then I have sex with you and something happens, if a pregnancy happens. If I don't really love a woman, I have to know all these things about her [menstrual cycle], so that when I have sex with her, there will not be any problems." 19-year-old single man with no children, middle education

- Condoms are abandoned as relationships stabilize; unintended pregnancies are common. There was a consensus that knowing each other well is essential before any longterm commitments are made; however, once trust has been built and a commitment established, most respondents find it difficult to maintain condom use. Both men and women reported reduced sexual pleasure and the desire for more intimacy as obstacles for continued condom use as a relationship progresses. Couples tended to switch to traditional methods, such as withdrawal or the calendar method. Yet, despite shifting toward these less reliable methods, respondents still had a strong desire not to have children. Although some respondents in a stable relationship made the conscious decision to use a modern contraceptive, most did not, and when faced with an unintended pregnancy, chose abortion to enable continuation of education or vocational training.

Many men seemed highly motivated to be in control of 
the traditional methods used by their female partners to ensure their effectiveness. Even so, traditional methods inevitably led to high numbers of unintended pregnancies (reported by 38 women and 15 men) and abortions (reported by 23 women and 11 men). For example, one woman had been highly motivated by HIV prevention campaigns and convinced her partner to use condoms, even though he was not in favor. Her vigilance lasted for a few months, until she became tired of the continuous arguments over condom use. She switched to the withdrawal method and became pregnant. She then aborted the pregnancy.

Giving birth before or shortly after marriage-to prove fertility-continues to be a common expectation in Ghanaian society, and respondents commonly reported discontinuing contraceptive use immediately after marriage. Even among the unmarried, if the relationship was considered serious, there was a tendency to let contraceptive use lapse. One 30-year-old woman with two children and high education had experienced an unintended pregnancy when she was a student. She explained "We were very close. He was almost like a fiancé....Sometimes without the condom we could have sex." In such situations, unintended pregnancies were more likely to be kept:

"I didn't think about [pregnancy]. I thought that it will happen after the wedding. It was something impromptu, so we just accepted it. He was very happy about it."-30year-old married woman with two children, middle education

Overall, sex before marriage seemed acceptable, in fact preferable, as having at least one child is very important, and a pregnancy before marriage may ensure that the union will produce children. As one respondent put it:

"If you marry and you are not able to have children, then it means that your marriage was useless. It is because of children that we marry."-28-year-old divorced woman with two children, low education

- More reliable methods are adopted after childbirth, but side effects limit consistent use. Regardless of marital status, once a couple has had a first child, the priority shifts toward birthspacing, primarily for the children's well-being. Most respondents-both men and women, of all ages and educational levels-expressed the desire to have three or fewer children. Economic challenges were cited as the main reasons, as they affect whether one can adequately care for offspring. One man explained:

"Spacing is important, and it all boils down to the income that you earn. Some people give birth to the next child the moment the first one takes its first steps....But if you realize that your income is not big, then you will have to space them out wide."-29-year-old single man with no children, low education

Similarly, one woman said:

"I think having too many children (sighs) creates problems. Because the children don't grow very well and they don't also get the proper care that they need. Things can get difficult for you. Talking about their schooling, today things have become very difficult financially."-30-year-old married woman with two children, high education

The tendency is then to approach a health provider for a more reliable method, mostly the injectable; almost all injectable users in our sample had at least one child. In many cases, partners were supportive of family planning use or even demanded it at this stage. One woman recounted:

"After I gave birth to our last born, he asked me to go and [get family planning], since he didn't want [me] to give birth again. He said that the children are many...so he made me go and do it. He said that he wanted a method that could last a long time, but I said I wanted something that could last for three months so that I will be able to identify any problem that may result. So, I had the injection and it has been very useful to me."-30-year-old married woman with three children, middle education

In other cases, women had taken unilateral action to protect themselves in the face of uncooperative partners. One woman, who switched to the injectable after using the rhythm method for three months, explained:

"If my husband was somebody who listens to me, I wouldn't even be going to the nurses for [family planning] (because she would still be using the rhythm method). But maybe sometimes I am in my danger period. The times that I am in my danger period, those are the times that he forces me, and it can bring about [pregnancy]."-30-year-old married woman with three children, low education

However, many respondents described how side effects led them to switch methods or discontinue contraceptive use. One woman, whose negative experience with the injectable made her switch to condoms, commented:

"I don't think I will do injection again because sometimes I will be bleeding for about two months. I continued bleeding and in fact, [the vagina] became tender, washing yourself was painful."-26-year-old married woman with one child, high education

Switching was often poorly supported by providers. For example, one woman, who had successfully used the injectable for five years until she was advised by her provider to take a break, explained:

"At that time, I was using [the injectable]. [The provider] told me that after five years, I could break for a while. So when I did break, I got pregnant again in less than three months, you see!"-35-year-old married woman with five children, low education

Sixteen women reported having experienced side effects of the injectable; the ability to cope with side effects seemed to be influenced by the nature of their relationships, as eight of the women who were in stable and supportive relationships continued with the method. Ambivalence about the relationship seemed to be linked with women's discontinuation of the injectable. Some women and men who disliked the side effects associated with the pill and the injectable perceived emergency contraception as a less harmful option and, thus, opted to use it regularly-either on its own or in combination. One woman said:

"With the [injectable], I wasn't having my menses.... It came to a time I was worried.... The [oral contraceptive 
pill] when I take it sometimes I have dizziness and then I feel like vomiting, nausea.... feel dryness in my vagina, so I chose not to use it again. When I take [emergency contraception], I don't feel any of the side effects....I just feel like myself, go [about] my daily activities so that is why I use it."-29-year-old married woman with one child, high education

Furthermore, the primacy of maintaining fertility exacerbates the fear of long-acting contraceptives that may be seen to inhibit future fertility. Misinformation from peers can dissuade use, as one woman explained:

"[A friend] told me that [the IUD] was not good. She also said that your womb can be sealed off and you can never be able to give birth again. She frightened me so much that I had to remove it later."-33-year-old widow with two children, low education

Inconsistent contraceptive use for child spacing can lead to unintended pregnancy and abortion, although fewer of both were reported among married or cohabiting partners who had started childbearing. For example, one 36-yearold married woman with two children and high education chose not to use a modern method because of weight gain on the pill and a reluctance to "put foreign things in my body." Instead, she opted for the calendar method, and although she considered that it "worked well," she reported having two unintended pregnancies; on both occasions, she used abortion for birthspacing. She explained "The first I kept. Second I didn't. Third I kept. Fourth I didn't."

- Modern methods are discontinued upon completion of childbearing. Only four older respondents-three women and one man-were explicit about not wanting any more children. Their contraceptive choices, however, did not support their intentions, and they were unable to prevent unintended pregnancy. Women who indicated that they had completed childbearing had switched back to less effective methods in an effort to minimize the effect of the "chemicals" on their bodies.

For example, one woman had her first sexual experience after marriage and did not use any contraceptives, because she wanted to start a family. She started using the pill after the birth of her first child. She later switched to the three-month injectable, which she continued to use until she had her third child, despite the fact that she experienced prolonged and heavy menstrual bleeding. She indicated that her husband, who is her only sexual partner, supported and encouraged her to use contraceptives. When they decided not to have any more children, they opted for the calendar method because of concerns about the harmful effects the injectable could have on her body. She explained:

"We thought about it and all these drugs, drugs that we take every day and inject every time, we don't know what side effect it has in our bodies. So we decided that we will not [use hormonal methods] again and so we used the [calendar method]."-38-year-old married woman with four children, middle education

The calendar method eventually failed her and she had her fourth child. Just after, the couple had unprotected sex and relied on emergency contraception. It was only then that they sought help from the clinic and, subsequently, the woman opted for tubal ligation.

\section{DISCUSSION}

Our analysis of contraceptive use by women and men in Accra has revealed clear patterns of contraceptive use at different relationship stages. We explored three layers of factors-individual actions, partner influences and social norms-and found that they interact at different relationship stages, and need to be analyzed and understood within a dynamic relationship context.

Both men and women had a strong desire to control fertility. A majority were doing something to prevent pregnancy at the time of the study, although they often used modern contraceptives irregularly and showed a preference for less effective methods. Moreover, the method used tended to depend on the type and stage of the relationship and was influenced by changing social norms regarding premarital sex and women's autonomy within relationships. Understanding contraceptive practices at different relationship stages has not been explicitly analyzed in the literature. This analysis sheds light on the reasons for the persistence of traditional method use at particular relationship stages in Ghana.

\section{Contraceptive Practices in the Context of Relationships}

Relationships take place within a social context where norms influence individuals' fertility decisions and contraceptive choices. Our findings confirm those of a previous study in Ghana that found that social norms help define the nature of relationships and of the roles men and women are expected to play vis-à-vis sexual behavior and contraceptive decisions. ${ }^{27}$ In addition, our findings suggest that social norms emerge concurrently with the continuation of traditional views. For example, although being a parent continues to be of great importance in Ghana, the responsibility of limiting children to a number that one can care for now carries increased weight. In terms of sexuality, abstaining from sex before marriage was not considered important by our respondents. In fact, premarital sex seemed to be encouraged to ensure fertility among women, and protecting female sexual innocence was only seen as an issue at the beginning of relationships. The pace of fertility decline has been especially rapid in the Greater Accra region, which is a context of far-reaching social change, including greater urbanization and literacy, increasingly cosmopolitan tastes and more positive attitudes toward smaller families. ${ }^{5}$ In this context, we found a strong motivation across respondent types to limit fertility and conscious decision making about when and whether to use modern or traditional contraceptive methods, or even abortion, depending on relationship stage.

At sexual debut and first sex with a new partner, women tended to act passively and were reticent to initiate discussion around sex; this has been previously reported. ${ }^{28}$ Such passivity undermines women's ability to negotiate con- 
dom use, which opens a window of risk. By contrast, men were aggressive in initiating sex and frequently coerced women, especially at sexual debut, as reported in other African studies. ${ }^{29-31}$

Nevertheless, many women challenged traditional social norms and used their agency to successfully negotiate condom use in the early stages of relationships. This finding has been discussed in more detail in relation to use of emergency contraception in Ghana, Burkina Faso and Senegal, ${ }^{15}$ and resonates with previous research findings that in South Africa, women in unions are able to insist on condom use. ${ }^{32}$ Furthermore, many men in our study were prepared to initiate condom use, both to protect against STIs and to avoid pregnancy, at least until they felt ready to look after a child. Some men assisted women's use of the calendar method to ensure that safe periods were properly observed. This echoes previous findings that point to significant involvement of men in regard to fertility and contraceptive decisions in Ghana. ${ }^{1,33}$

The high value put on childbearing in Ghana exacerbates respondents' fear that long-acting methods will have adverse effects on future fertility. Thus, once a stable relationship is formed, most couples switch to traditional methods until fecundity is proven. This clear preference for traditional methods has been described in a study from Cameroon, ${ }^{34}$ which points out that women who use the calendar method do not have an unmet need, nor are they less motivated to avoid pregnancy or less aware of modern contraception. Instead, they have a social motivation to act as "modern women" and perceive traditional method use as "honorable," as it provides evidence of the virtues of self-restraint and discipline, while not jeopardizing future fertility. Nevertheless, use of traditional methods or inconsistent condom use in a stable sexual relationship creates another window of risk of unintended pregnancy.

Most respondents reported that after fertility is proven, couples with at least one child are willing-even eager-to use more effective contraceptive methods to space their children, perhaps an indication of the successful messaging of family planning in Ghana as a birthspacing tool. At this stage in the relationship, the main difficulty for couples wishing to practice contraception is dissatisfaction with modern methods. Side effects (especially menstrual irregularity) and apprehension about impairing future fertility have been widely cited in other studies, and contribute to both method nonuse and discontinuation. ${ }^{35-38}$ Fear of side effects remains the most frequently cited method-related reason for contraceptive nonuse among married women in Ghana-reported by 26\% in 2008. ${ }^{1}$ Again, in our study, the relationship stage and quality mattered, as side effects reported by women using the injectable prompted different responses: Women in supportive relationships seemed determined to continue to use the injectable, whereas those who were unsure of their relationship discontinued or switched to other, usually less-effective, methods.

Finally, after couples' reproductive intentions were realized, women tended to switch from hormonal methods back to traditional methods to prevent further perceived contamination of the body. This switch, however, often undermined their desire to avoid further pregnancies.

Our findings support Johnson-Hanks' interpretation of women's choice of traditional methods as a socially reasoned decision to control fertility. ${ }^{34}$ Our study goes further by identifying specific relationship stages at which motivated men and women will favor traditional methods over modern ones; these new findings on contraceptive behaviors in West Africa help explain the large difference between current- and ever-use of modern contraceptives among women of reproductive age in Ghana (19\% and $50 \%$, respectively). ${ }^{1}$

Furthermore, our findings on the important role of men in fertility decision making at different relationship stages add to the limited literature by pinpointing the nature of their influence. Men may initiate condom use early in relationships; actively facilitate women's use of the calendar method, in both stable and unstable relationships, at times when this is the method of choice; and, in some cases, support women experiencing side effects of modern contraceptives, thereby reducing discontinuation.

\section{Program Implications}

Despite the usual generalizability challenges associated with qualitative research, this study among a large and diverse sample of men and women in Accra sheds light on women's and men's use of contraceptives in Ghana. Our analysis revealed that couples are exposed to windows of risk of unintended pregnancy and unsafe abortion at multiple occasions across a relationship's trajectory through their conscious choice to use traditional methods at these stages. This suggests a need to reexamine the place of traditional methods in family planning counseling and service provision. Historically, family planning programs have not disseminated information about or promoted the use of traditional methods, focusing instead on highly effective modern methods. Nevertheless, it seems essential that providers commit adequate time to help both men and women understand the menstrual cycle, particularly those who opt to use traditional methods.

In addition, providers might suggest that stable couples use a more effective contraceptive regimen (such as condoms, with emergency contraception in case of failure or nonuse) during periods when they prefer to avoid prolonged use of hormonal contraceptives. Also, providers need to discuss method-related side effects with their clients, and help them find the best method to fit their needs.

Finally, our sample was biased toward educated men and women and those using contraceptives. Nevertheless, this makes our findings regarding informed preferences for use of traditional methods even more convincing. Contraceptive programs may be more effective if they frame messages for people at different relationship stages, involve men as part of couples and work with people's desires to use traditional methods at certain times to ensure they can do so effectively. 


\section{REFERENCES}

1. Ghana Statistical Service (GSS), Ghana Health Service (GHS) and ICF Macro, Ghana Demographic and Health Survey, 2008, Accra, Ghana: GSS, GHS and ICF Macro, 2009.

2. ICF Macro, Trends in Demographic, Family Planning, and Health Indicators in Ghana, 1960-2008: Trend Analysis of Demographic and Health Surveys Data, Calverton, MD, USA: ICF Macro, 2010.

3. Blanc AK and Grey S, Greater than expected fertility decline in Ghana: untangling a puzzle, Journal of Biosocial Science, 2002, 34(4):475-495.

4. Cleland J and Sinding S, What would Malthus say about AIDS in Africa? Lancet, 2005, 366(9500):1899-1901

5. Agyei-Mensah S, Fertility transition in Ghana: looking back and looking forward, Population Space and Place, 2006, 12(6):461-477.

6. Aniteye $\mathrm{P}$ and Mayhew SH, Shaping legal abortion provision in Ghana: using policy theory to understand provider-related obstacles to policy implementation, Health Research Policy and Systems, 2013, 11(1):23

7. Ahiadeke C, Incidence of induced abortion in Southern Ghana, International Family Planning Perspectives, 2001, 27(2):96-101 \& 108

8. Mayhew SH and Adjei S, Sexual and reproductive health: challenges for priority setting in Ghana's health reforms, Health Policy and Planning, 2004, 19(Suppl. 1):i50-i61.

9. Adongo PB, Phillips JF and Binka FN, The influence of traditional religion on fertility regulation among the Kassena-Nankana of northern Ghana, Studies in Family Planning, 1998, 29(1):23-40.

10. Binka $\mathrm{F}$ et al., Assessing population dynamics in a rural African society: the Navrongo demographic surveillance system, Journal of Biosocial Science, 1999, 31(3):375-391.

11. Debpuur $C$ et al., The impact of the Navrongo Project on contraceptive knowledge and use, reproductive preferences, and fertility, Studies in Family Planning, 2002, 33(2):141-164.

12. Phillips JF, Bawah AA and Binka FN, Accelerating reproductive and child health programme impact with community-based services: the Navrongo experiment in Ghana, Bulletin of the World Health Organization, 2006, 84(12):949-955.

13. White MJ et al., Urbanization and fertility: an event-history analysis of coastal Ghana, Demography, 2008, 45(4):803-816

14. Osei I, Exploring the opportunities and challenges to the use of emergency contraception in Accra, Ghana, doctoral thesis, London: London School of Hygiene \& Tropical Medicine, 2009.

15. Teixiera M et al., Representations and uses of emergency contraception in West Africa. A social anthropological reading of a northern medicinal product, Social Science \& Medicine, 2012, 75(1):148-155.

16. Mayhew SH et al., Provider attitudes to emergency contraception in Ghana and Burkina Faso, Population, 2013, 68(1):115-139.

17. Bassey EA et al., Awareness, attitude and practice of contraception among secondary school girls in Calabar, Nigeria, Nigerian Journal of Medicine, 2005, 14(2):146-150.

18. Orji EO and Onwudiegwu U, Prevalence and determinants of contraceptive practice in a defined Nigerian population, Journal of Obstetrics \& Gynaecology, 2002, 22(5):540-543.

19. Adih WK and Alexander CS, Determinants of condom use to prevent HIV infection among youth in Ghana, Journal of Adolescent Health, 1999, 24(1):63-72.

20. Polacsek $\mathrm{M}$ et al., Correlates of condom use stage of change: implications for intervention, AIDS Education and Prevention, 1999 11(1):38-52.

21. Ezeh AC, The influence of spouses over each other's contraceptive attitudes in Ghana, Studies in Family Planning, 1993, 24(3):163-174.

22. Harper CC, Minnis AM and Padian NS, Sexual partners and use of emergency contraception, American Journal of Obstetrics \& Gynecology, 2003, 189(4):1093-1099.

23. Kohler HP, Behrman JR and Watkins SC, The density of social networks and fertility decisions: evidence from South Nyanza district,
Kenya, Demography, 2001, 38(1):43-58.

24. Wengraf T, Qualitative Research Interviewing: Biographic Narrative and Semi-Structured Methods, Sage: London, 2001

25. Baddeley J and Singer JA, Charting the life story's path: narrative identity across the life span, in: Jean CD, ed., Handbook of Narrative Inquiry: Mapping a Methodology, Thousand Oaks, CA, USA: Sage Publications, 2007, pp. 177-202

26. Miles $\mathrm{MB}$ and Huberman AM, Qualitative Data Analysis: An Expanded Sourcebook, second ed., Thousand Oaks, CA, USA: Sage Publications, 1994

27. Feyisetan BJ, Phillips JF and Binka F, Social interaction and contraceptive change in northern Ghana, African Population Studies, 2003, 18(2):47-67.

28. Moore AM, Gender role beliefs at sexual debut: qualitative evidence from two Brazilian cities, International Family Planning Perspectives, 2006, 32(1):45-51.

29. Glover EK et al., Sexual health experiences of adolescents in three Ghanaian towns, International Family Planning Perspectives, 2003 29(1):32-40.

30. Erulkar AS, The experience of sexual coercion among young people in Kenya, International Family Planning Perspectives, 2004, 30(4):182-189.

31. Jewkes $\mathrm{R}$ et al., Rape of girls in South Africa, Lancet, 2002 $359(9303) \cdot 319-320$

32. Maharaj P and Cleland J, Risk perception and condom use among married or cohabiting couples in KwaZulu-Natal, South Africa, International Family Planning Perspectives, 2005, 31(1):24-29.

33. DeRose LF and Ezeh AC, Men's influence on the onset and prog ress of fertility decline in Ghana, 1988-98, Population Studies, 2005, 59(2):197-210

34. Johnson-Hanks J, When the future decides: uncertainty and intentional action in contemporary Cameroon, Current Anthropology, 2005, 46(3):363-385.

35. GSS, Noguchi Memorial Institute for Medical Research and ORC Macro, Ghana Demographic and Health Survey, 2003, Calverton, MD, USA: ORC Macro, 2004

36. Osei I et al., What happened to the IUD in Ghana? African Journal of Reproductive Health, 2005, 9(2):76-91.

37. Solo J et al., Ghana Case Study: 'Give Them the Power,' Repositioning Family Planning, New York: ACQUIRE Project/EngenderHealth, 2005.

38. Williamson LM et al., Limits to modern contraceptive use among young women in developing countries: a systematic review of qualitative research, Reproductive Health, 2009, 6(1):3.

\section{RESUMEN}

Contexto: A pesar de la decreciente fecundidad en Ghana, el uso de anticonceptivos modernos, incluso en áreas urbanas, es bajo por razones que todavía no son claras. Pocos estudios han explorado qué determina las decisiones sobre fecundidad y uso de anticonceptivos entre los actuales residentes urbanos en el contexto de una relación.

Métodos: Se condujeron entrevistas en profundidad sobre la historia de vida anticonceptiva de una muestra intencional de 80 mujeres y hombres sexualmente activos habitantes de Accra.

Resultados: La anticoncepción se percibió de manera favorable, aunque la oportunidad y elección del método depende fuertemente del tipo y la etapa de la relación. En el momento del debut sexual y de la primera relación sexual con una nueva pareja, el encuentro sexual ocurre usualmente sin protección. Muchas mujeres muestran voluntad para subsecuentemente negociar el uso del condón; los hombres también muestran mo- 
tivación de practicar la anticoncepción. Conforme la relación se estabiliza, las parejas abandonan los condones y adoptan métodos tradicionales por temor a que los métodos modernos puedan afectar la fecundidad. Después del primer nacimiento, las parejas prefieren los anticonceptivos modernos para espaciar los siguientes nacimientos, pero los efectos secundarios muchas veces conducen a las mujeres a cambiar de método o a discontinuar su uso; las mujeres que tienen una relación con una pareja que les brinda apoyo tienen mayor probabilidad que las que no cuentan con ese apoyo de continuar usando anticonceptivos modernos a pesar de los efectos secundarios. Una vez que las metas reproductivas se han alcanzado, las parejas regresan al uso de métodos tradicionales pare evitar una mayor exposición a "sustancias químicas."

Conclusiones: Los programas anticonceptivos pueden ser más exitosos si dirigen sus mensajes dependiendo de la etapa en la que se encuentra la relación, involucran a los hombres y trabajan con los deseos de las personas de usar métodos tradicionales en ciertos momentos, para asegurar que lo puedan hacer de manera segura.

\section{RÉSUMÉ}

Contexte: Malgré une fécondité en baisse au Ghana, la pratique de la contraception moderne, même dans les milieux urbains, reste faible pour des raisons qui demeurent obscures. Peu d'études ont examiné la dynamique des décisions de fécondité et de la pratique contraceptive parmi les résidents urbains contemporains dans le contexte d'une relation.

Méthodes: Des entretiens en profondeur sur les antécédents contraceptifs ont été menés dans un échantillon délibéré de 80 femmes et hommes sexuellement actifs d'Accra.

Résultats: La contraception s'est révélée bénéficier d'une perception favorable, bien que le moment et le choix de la méthode dépendent fortement du type et du stade de la relation. Lors des premiers rapports sexuels et à la première rencontre sexuelle avec un nouveau partenaire, les rapports sont généralement non protégés. Beaucoup de femmes font preuve d'autodétermination ("agency») dans la négociation ultérieure du préservatif. Les hommes se montrent aussi motivés à pratiquer la contraception. Tandis que la relation se stabilise, les couples abandonnent le préservatif au profit de méthodes traditionnelles, de crainte que les méthodes modernes n'affectent leur fécondité. Après une première naissance, les couples préfèrent la contraception moderne, à des fins d'espacement, mais les effets secondaires mènent souvent les femmes à changer de méthode ou à abandonner la pratique. Les femmes qui bénéficient d'une relation de soutien sont plus susceptibles de poursuivre la pratique de la contraception moderne en dépit de ses effets secondaires. Une fois atteints les objectifs de procréation, les couples reviennent aux méthodes traditionnelles afin d'éviter plus d'exposition à des «produits chimiques».

Conclusions: Les programmes de contraception remporteraient peut-être plus de succès s'ils ciblaient leurs messages en fonction du stade de la relation, impliquaient les hommes et tenaient compte du désir de pratiquer, à certains moments, les méthodes traditionnelles, afin d'assurer qu'elles le soient sans risques.

\section{Acknowledgments}

This research is part of the Emergency Contraception for Africa (ECAF) project funded by the European Commission (project number 56-7894) in 2005-2009 and coordinated by the Institut national de la santé et de la recherche médicale (Inserm). The ECAF team members are Nathalie Bajos and Maria Teixeira, Inserm, Paris; Michèle Ferrand, Centre national de la recherche scientifique, Paris; Agnès Guillaume and Agnès Adjamagbo, Institut de recherche pour le développement, Marseille, France; Clémentine Rossier, Institut national d'études démographiques, Paris; Banza Baya, André Soubeiga and Nathalie Sawadogo, Institut superieur des sciences de la population, University of Ouagadougou, Burkina Faso; Fatima Bakass and Aziz Chaker, Institut national de statistique et d'économie appliquée, Rabat, Morocco; John Gyapong, Leticia Beikro and Ivy Osei, Health Research E Development Division, Ghana Health Service, Accra, Ghana; Pierrette Aguessy Koné, Association Santé reproductive et genre, Dakar, Senegal; Catherine Gourbin and Lorise Moreau, University of Louvain-la-Neuve, Belgium; and Susannah Mayhew and Martine Collumbien; London School of Hygiene \& Tropical Medicine.

Author contact:Susannah.Mayhew@lshtm.ac.uk 